\title{
Tribute Issue: Remembering Ji-Hyung Cho
}

The Asian Review of World Histories believes that there can be several world histories, not just the one. Advocating critical enquiry into world-historical categories, promoting analytical reviews of world-historical trends and endorsing subject surveys and literature reviews on world-historical themes, the ARWH welcomes contributions on research in, and the teaching of, world history.

Articles in the ARWH are global in scale, but they also highlight localized responses to global concerns, emphasizing as well place-based, specific solutions that transcend national boundaries and conventional regional frames. At the critical interface between the global and the local, as two of the articles in this issue (Haneda for Japan and Hwangbo for Korea) affirm, this issue of ARWH contains in addition two articles on the theme of mobility versus fixity through the lens of migration and empire (Manning) and the return of the continental as opposed to the maritime (Wang), as well as a review essay on the significance of climate history to world-historical analyses (Burke). As Burke notes in his essay, "when we expand our field of vision from individual societies and civilizations to the world as a whole, what we see changes in fundamental ways. Only at the global level can we recognize how the modern world has been shaped not only by human action, but also by large scale environmental transformations." This issue therefore is also about the cognitive shift from bounded national units to the unfettered global sphere and welcomes you to share in this exciting voyage of discovery. 
This issue of the ARWH is our tribute to the late Ji-Hyung Cho, founder of the ARWH and one of the leading figures of the Asian Association of World Historians. For a more detailed biography of Ji-Hyung Cho, see his obituary by Patrick Manning in this issue.

Rila MUKHERJEE

Chief Editor of the ARWH

On the behalf of the Editorial Board

July 2015 